Revista de

Contabilidade e

Organizações

www.rco.usp.br
DOI: http://dx.doi.org/10.11606/rco.v10i26.106048

Journal of

Accounting and

Organizations

\title{
Transações de insiders e impacto na rentabilidade e valor das empresas brasileiras
}

\author{
Rogéria de Freitas Vasconcelos ${ }^{\mathrm{a}}$; Fernando Caio Galdi ${ }^{\mathrm{a}}$; Danilo Soares Monte-Mor ${ }^{\mathrm{a}}$
}

${ }^{a}$ Fucape Business School

\section{Informações do Artigo}

Histórico do Artigo

Recebido: 19 de outubro de 2015

Aceito: 11 de abril de 2016

\section{Palavras-chave:}

Insider trading.

Valor de mercado.

Rentabilidade.

\begin{abstract}
Resumo
Este estudo investiga se existe relação entre o volume de transações de compra e venda de ações da companhia conduzidas por insiders e o valor de mercado e/ou rentabilidade das empresas brasileiras listadas na BM\&FBovespa. A seleção da amostra utilizada neste estudo considera a coleta de dados não estruturados enviados pelas empresas à Comissão de Valores Mobiliários (pelo sistema IPE-CVM) e dados obtidos no sistema Economática ${ }^{\circledR}$ para o período entre o primeiro trimestre de 2007 e o último trimestre de 2011. Os resultados obtidos, embora indiquem que não há indícios de relação significativa do volume de transações realizados por insiders tanto no preço quanto na rentabilidade da empresa, sugerem que existe uma efeito positivo entre posições compradas assumidas por insiders e a média trimestral do valor de mercado. Tais resultados sugerem que, independente do valor transacionado, posições compradas por parte dos insiders tem potencial para sinalizar aumentos do valor de mercado das empresas brasileiras.
\end{abstract}

Copyright (C) 2016 FEA-RP/USP. Todos os direitos reservados

\section{INTRODUÇÃO}

Existe uma grande preocupação com o fluxo de informações privilegiadas no ambiente corporativo, uma vez que, de posse dessas informações, executivos podem obter vantagens sobre a compra ou a venda de ações caso dados relevantes não sejam divulgados de forma oportuna ao mercado (AIER, 2013; PIOTROSKI e ROULSTONE, 2005). Nesse contexto, é amplamente discutido o conceito de insider trading, o qual pode ser definido como qualquer operação realizada com ações em proveito próprio e pessoal pelos gestores de uma empresa e com base em informações não compartilhadas por outros acionistas (FIDRMUC; GOERGEN e RENNEBOOG, 2006).

Uma série de casos de insider trading relativos a empresas de grande porte tem sido documentada no Brasil, como os casos da Kibon e Petrobrás em 1977 (MOURA, 1979), Submarino em 2006, Gol em 2007 e Sadia em 2009, dentre outros casos que ainda estão em julgamento, como o processo aberto em 2013 contra o empresário Eike Batista. Uma vez que notícias privilegiadas podem afetar o comportamento das ações da firma (DAHER; KARAM e MIRMAN, 2012), existe uma preocupação da Comissão de Valores Mobiliários (CVM) em regular as movimentações das empresas no que tange às informações relevantes, de forma a mitigar a ocorrência de negociações que por vezes assumam um caráter ilegal ou que potencialmente manipulem o comportamento do mercado.

Diversos trabalhos apresentam argumentos que Insiders, por possuírem conhecimento de informações em um período ex-ante à divulgação para o mercado, possuem capacidade privilegiada de negociação quando comparada à dos demais acionistas (Bebchuk e Cohen, 2005; Gunny, Ke e Zhang, 2009; e Bebchuk e Weisbach, 2010). Tais resultados sugerem que a compra (venda) de papeis por parte dos insiders sinalizam uma antecipação de resultados futuros positivos (negativos) da empresa. Como boas (más) notícias afetam em média o preço de forma positiva (negativa), espera-se que transações líquidas de insiders, ao sinalizarem alterações nas expectativas futuras do lucro, estejam positivamente associadas tanto com o valor de mercado da empresa quanto com a rentabilidade da empresa. Partimos da premissa que o mercado brasileiro é eficiente na forma fraca ou semi-forte conforme relatado em estudos como Haque et al (2001) e Ratner e Leal (1999). Assim, pode-se considerar que os 
insiders têm informações privadas que não estão incorporadas nos preços de mercado (por exemplo: informações sobre projetos de investimentos, comportamento das vendas, etc).

O presente estudo tem como objetivo investigar se existe associação entre o volume de transações de compra e venda de ações conduzidas por insiders no mercado brasileiro e o seu valor de mercado e/ou rentabilidade das empresas. Ressalta-se que a avaliação é feita e relação insider trading legal, ou seja, negociação por pessoas internas à empresa, que possuem mais informação do que a média do mercado e, portanto, possuem maior capacidade de avaliar a performance futura da empresa.

Para Fidrmuc, Goergen e Renneboog (2006), o principal elemento a favor de um insider é a capacidade privilegiada de negociação da informação que possui. Gunny, Ke, Zhang (2009), Bebchuk e Cohen (2005) e Bebchuk e Weisbach (2010) ponderam potenciais problemas decorrentes dessa posição: diante de uma expectativa negativa de desempenho da firma, um insider lucra quando vende suas ações antes da divulgação oficial dessa notícia. Nesse caso, tal posição permitiria uma antecipação por parte do insider à queda dos preços dos papéis da empresa decorrentes da comunicação da má notícia ao mercado. Por outro lado, se a performance esperada é positiva, um insider lucra quando decide manter as suas ações por um período maior de tempo ou quando aumenta a sua posição na empresa. Isso por que, como retorno e aumento das expectativas de lucro estão positivamente correlacionados, o insider aumenta as suas probabilidades de receber um retorno superior ao que teria após a divulgação da notícia caso tal informação não tivesse sido utilizada.

Aktas et al. (2008) investigam se o insider trading legal contribui para a eficiência de mercado e utilizam o mercado norte-americano como base para a avaliação. Os autores concluem que embora o mercado não responda fortemente em termos de retorno anormal às atividades de insider trading, a mudança significativa na sensibilidade dos preços para um desequilíbrio de ordens devido à atividade de insider trading anormal revela que a descoberta de preço é acelerada em dias em que este evento ocorre. Adicionalmente, estudos clássicos sobre insider trading como Lorie e Niederhoffer (1968) e Finnerty (1976) concluem que insiders conseguem obter ganhos anormais negociando ações de suas empresas. Assim, a relação esperada entre rentabilidade e negociação de insiders é positiva no sentido de que o insider tem acesso antecipado às informações privadas, portanto sua tomada de decisão tende a ser antecipada em relação ao mercado.

A definição para insider trading e insider, neste trabalho, é a mesma adotada conforme a instrução 358 de 2002 da Comissão de Valores Mobiliários (CVM). O termo insider se refere a toda pessoa que, em virtude de fatos circunstanciais, tem acesso a informações relevantes e exclusivas, pertinentes ao negócio da firma. As transações de compra e venda por insiders foram analisadas à luz do acionista controlador e dos órgãos executivos da empresa: conselho administrativo, o conselho fiscal e a diretoria. (OLIVEIRA, 2001; CERVO, BERVIAN, SILVA, 2007; MALHOTRA, 2006; MARTINS, THEOPHILO, 2007).

Telder (2011) escreveu sobre o grande volume de informações relevantes divulgadas ao público e o impacto que elas podem causar na negociação de valores mobiliários. Segundo o autor, todos os detalhes que possam alterar o valor das ações devem ser amplamente divulgados. Uma vez que informações privilegiadas possibilitam a obtenção de ganhos acima dos esperados pelo mercado, espera-se que exista uma relação significativa entre insider trading e o retorno sobre ativos (ROA) e o valor médio da empresa. Vale salientar que não necessariamente insider trading é crime. Parente (1978) relata que este ato não constitui ilícito, em princípio, uma transação de compra ou venda de ações realizada por insider, mas caso a transação seja revestida de características que gerem benefícios ao insider decorrente de informação não pública, há a caracterização do crime.

Para que fosse possível investigar se existe relação entre o volume de transações de compra e venda de ações da companhia conduzidas por insiders e o seu valor de mercado e/ou rentabilidade das empresas brasileiras, utilizou-se dados trimestrais das 100 empresas mais líquidas listadas na BM\&FBovespa e com registro ativo na CVM. Como proxy para o volume de transações efetuado por insiders (Técnico Executivo, Diretores, Conselheiros Fiscais, Conselheiros Administrativos e Acionista Controlador), utilizou-se o valor das movimentações de compra e venda de ações por parte desses agentes.

A seleção da amostra utilizada neste estudo considera a coleta de dados não estruturados enviados pelas empresas à Comissão de Valores Mobiliários e dados obtidos no sistema Economática ${ }^{\circledR}$ para o período entre o primeiro trimestre de 2007 e o último trimestre de 2011. No site da CVM foram obtidas as informações do volume transacionado por insiders que constam no Sistema de Envio de Informações Periódicas e Eventuais (IPE), um sistema desenvolvido conjuntamente com a BM\&FBovespa no intuito de facilitar o cumprimento das regras pelas companhias. No Economática ${ }^{\circledR}$ foram coletados os indicadores financeiros referentes às demais variáveis utilizadas: média trimestral do valor por ação, rentabilidade e volume transacionado de ações. As estimações dos modelos empíricos propostas foram feitas em painel com efeito fixo, adicionalmente à utilização de outras variáveis de controle para que fosse possível controlar por heterogeneidades existentes entre as empresas analisadas (receita, 
dívida bruta ativo total, despesas com vendas e administrativas).

Os resultados obtidos sugerem que variações do percentual de transações insider com relação ao total transacionado não têm potencial para sinalizar alterações na rentabilidade das empresas brasileiras, o que rejeita a hipótese de que posições compradas de insiders estão associadas em média à um aumento da rentabilidade. Nesse caso, os resultados sugerem que no mercado brasileiro as transações de insiders não sinalizam em média antecipação de alterações do lucro das empresas.

Análises adicionais apresentam ainda indícios de que, embora o volume transacionado não apresente efeito significativo no preço das ações, a posição comprada por parte dos insiders está positivamente associada à um aumento do valor de mercado das empresas, o que suporta a hipótese de que posições compradas de insiders estão associadas em média à um aumento do valor de mercado das empresas. Tais evidências estão alinhadas aos resultados obtidos por Gunny, Ke, Zhang (2009), Bebchuk e Cohen (2005) e Bebchuk e Weisbach (2010), os quais sugerem que a manutenção da posição comprada por parte dos insiders por um maior período de tempo ou o aumento de tal posição aumentam as probabilidades da obtenção de retornos positivos.

Os resultados obtidos, portanto, corroboram com a hipótese de que operações de insider trading estão associadas positivamente com valor de mercado médio da empresa, mas não fornecem embasamento estatístico que sustente a hipótese de que operações de insider trading estão associadas à rentabilidade das empresas. Outras análises ainda indicam que não se pode afirmar a existência de um comportamento sistemático de efeito tanto na rentabilidade quanto no valor das empresas por transações realizadas por insiders isolados.

Segundo Telder (2011), uma maior clareza e controle da divulgação das informações pode evitar o favorecimento de determinados grupos e reduzir a assimetria informacional existente entre gestores e stakeholders. Com base nos resultados obtidos, um maior rigor com relação à divulgação das informações pode contribuir para que seja minimizado o potencial impacto negativo dessas condutas na variação do preço das ações e no valor das empresas brasileiras.

Este artigo segue estruturado da seguinte forma: na próxima seção serão apresentadas informações acerca dos aspectos legais que envolvem o insider trading, bem como os principais casos brasileiros e resultados da literatura referentes ao impacto dessas transações no valor das empresas. Na seção 3 será apresentado o design da pesquisa. A seção 4 se destina aos resultados. A última seção se destina à conclusão e demais comentários.

\section{INSIDER TRADING}

Pesquisas relacionadas à utilização de informações contábeis como dados relevantes para a avaliação de empresas foram intensificadas a partir da década de 1960, quando pesquisadores como Ball e Brown (1968) e Beaver (1968) apresentaram análises sobre como variáveis contábeis se relacionam com o valor das empresas e de que forma poderiam ser utilizadas na formação de estratégias para a obtenção de crédito e alocação mais eficiente de recursos.

Atualmente, diversas pesquisas têm sido feitas no sentido de avaliar como as informações financeiras e operacionais interferem no processo de decisão e avaliação da empresa (BARTH; BEAVER; LANDSMAN, 2001). A importância e a qualidade das informações são fundamentais para os diversos agentes do mercado de capitais, tanto para reduzir a assimetria informacional, quanto para reduzir os conflitos de agência (PALEPU e HEALY, 2001).

Perez e Fama (2006) pesquisaram o mercado de capitais brasileiro e afirmam que "uma das razões para a relevância da informação contábil para o usuário externo recai sobre a sua capacidade de redução da assimetria informacional". Para Fidrmuc, Goergen e Renneboog (2006), o principal elemento a favor de um insider é a capacidade privilegiada de negociação da informação que possui e de trabalhar em cima da assimetria criada entre tais agentes e o mercado.

Nesses casos, o Insider Trading torna-se prejudicial para o desenvolvimento do mercado de capitais uma vez que eleva os custos de assimetria informacional, fazendo com que a avaliação e a precificação da firma sejam feitas de forma equivocada (BAGEHOT, 1999). Com a falta de confiança no mercado de capitais, os agentes econômicos poupadores tendem a alocar suas reservas em investimentos mais seguros e com informações mais simétricas. A falta de credibilidade nos mercados ocasiona a redução do número de negociações em bolsa de valores e, consequentemente, uma redução da liquidez de mercado. 
Uma série de casos de insider trading relativos a empresas de grande porte tem sido documentada no Brasil. Uma vez que notícias privilegiadas podem afetar o comportamento das ações da firma (DAHER; KARAM e MIRMAN, 2012), existe uma preocupação da Comissão de Valores Mobiliários (CVM) em regular as movimentações das empresas no que tange às informações relevantes, de forma a mitigar a ocorrência de negociações que por vezes assumam um caráter ilegal ou que potencialmente manipulem o comportamento do mercado e aumentem a assimetria de informação.

Akerlof (1970) foi o primeiro a analisar as implicações da assimetria de informação. No artigo "The Market for 'Lemons': Quality Uncertainty and the Market Mechanism”, o autor relata como os agentes que possuem informação privilegiada sobre o ativo negociado obtêm um ganho por utilizá-la (insider trading) no momento da transação com um agente desinformado. Nesse caso, espera-se que tanto a rentabilidade quanto o valor de mercado das empresas sejam afetados na presença de insider tradings.

Estudos incluindo Gunny, Ke, Zhang (2009), Bebchuk e Cohen (2005) e Bebchuk e Weisbach (2010) ponderam que quando informações são utilizadas por parte dos insiders sem a correta divulgação para os stakeholders, criam-se potenciais problemas decorrentes da assimetria gerada: diante de uma expectativa negativa de desempenho da firma, um insider lucra quando vende suas ações antes da divulgação oficial dessa notícia. Nesse caso, tal posição permitiria uma antecipação por parte do insider à queda dos preços dos papéis da empresa decorrentes da comunicação da má notícia ao mercado. Por outro lado, se a performance esperada é positiva, um insider lucra quando decide manter as suas ações por um período maior de tempo ou quando aumenta a sua posição na empresa. Isso por que, como retorno e aumento das expectativas de lucro estão positivamente correlacionados, o insider aumenta as suas probabilidades de receber um retorno superior ao que teria após a divulgação da notícia caso tal informação não tivesse sido utilizada. A partir dessas relações, formulam-se as seguintes hipóteses:

H1: Posições compradas de insiders estão associadas em média à um aumento da rentabilidade das empresas;

H2: Posições compradas de insiders estão associadas em média à um aumento do valor de mercado das empresas;

\subsection{Casos de insider trading no Brasil}

Diversos casos de insider trading no Brasil são relatados na bibliografia especializada, tal como em Moura (1979), que discorre sobre as empresas Kibon e Petrobras. Os dois casos ocorreram no ano de 1977. Apesar das evidências de uso de informação privilegiada pela administração dessas empresas, a CVM não iniciou processo e fez acordo com a Kibon. Quanto à Petrobras, a comissão alegou impossibilidade de se constatar a violação do dever de lealdade de informar (art. 155 e 157, Lei 6404/07).

O primeiro caso julgado no Brasil referente a essa atividade refere-se à Sadia, no qual um ex-diretor, Luiz Gonzaga Murat Júnior, e um ex-integrante do conselho de administração da empresa, Romano Ancelmo Fontana Filho, foram condenados criminalmente por Insider trading. No mês de abril de 2006, os insiders tiveram acesso a informações privilegiadas da oferta pública da Sadia pelo controle acionário da então concorrente Perdigão, o qual ocorreria três meses depois. Desse modo, lucraram negociando ações da Perdigão na Bolsa de Valores de Nova York (NYSE). No mesmo mês, quando a proposta foi aprovada pelo conselho da Sadia, Murat fez a primeira compra de ações da Perdigão na NYSE, comprando 15.300 ADRs (american depositary receipts) a US\$ 23,07 cada papel. Em junho, conhecedor da proximidade do anúncio do negócio, o executivo comprou mais 30.600 ADRs, elevando sua carteira para 45.900 ações, a US\$ 19,17 cada papel. Cada compra ocorreu mediante informações privilegiadas acerca do andamento da oferta da Sadia pela Perdigão, o que caracterizou duplamente um crime de insider trading.

Em 21 de julho, assim que soube que a Sadia havia desistido de comprar a Perdigão, Murat esperou que a decisão se tornasse pública e vendeu as ações, tendo um lucro menor que o esperado. A venda, nesse caso, não foi considerada crime pelo Ministério Público Federal (MPF), pois foi realizada após a devida publicidade da revogação da oferta. Fontana Filho incorreu quatro vezes no crime de insider trading, pois efetuou quatro operações de compra e venda mediante informações privilegiadas. $\mathrm{O}$ executivo comprou três lotes da Perdigão, totalizando 18 mil ações, na Bolsa de Nova York, por US\$ 344.100, entre 5 e 12 de julho de 2006, poucos dias antes do anúncio da oferta. Ele vendeu todas as ações em 21 de julho de 2006, mesmo dia da recusa da Perdigão, por US\$ 483.215,40, lucrando US\$ 139.114,50. A venda, entretanto, deu-se antes da publicação da desistência da 
Sadia e, por isso, foi considerada crime pelo MPF (MPF-PGR, 2011).

Outro caso de insider tranding aponta que o advogado Marcos Meira, conhecido como amigo dos proprietários da Gol Linhas Aéreas, teria se beneficiado por meio de informações privilegiadas. A acusação aponta que ele realizou sua primeira operação em bolsa em 23/03/07, comprando 9.000 ações da Gol, no valor de R \$ 499.555,00. Tal posição foi alienada em 30/03/07, por R \$ 581.690,00, resultando em um lucro bruto de R\$ $82.135,00$, equivalente a 16,4\% do investimento. Questionado pela CVM, o acusado alegou ter realizado várias operações de compra e venda de ações, buscando oportunidades que surgissem no mercado.

A acusação enfatiza que "a compra das ações da Gol que efetivou em 2007 foi a primeira operação em bolsa de valores que realizou em toda a sua vida" e que as operações foram 65 negócios com ações emitidas por nove companhias, entre os dias 23/03 e 26/06/07. No período de julho de 2007 a novembro de 2008, ele não teria realizado mais quaisquer outras operações em bolsa de valores. O total dos negócios de compra e venda foi de R\$ 1,78 milhão, sendo que a parcela relativa às operações de compra e venda com ações de emissão da Gol atingiu $\mathrm{R} \$ 1,1$ milhão.

De acordo com processo administrativo sancionado na CVM, № 19/2009, com base na prova dos autos e na legislação aplicável, por unanimidade de votos, decidiu-se aplicar ao acusado Marcos José Santos Meira a penalidade de multa pecuniária no valor de R $\$ 164.270,00$, por utilização de informação privilegiada em seus negócios no mercado de valores mobiliários (Caso de Insider Trading Gol, 2011). Também se pode citar o caso da cervejaria Ambev, investigado pela CVM a respeito das negociações realizadas pelos acionistas majoritários e pela direção executiva da empresa, antes da fusão da companhia com a cervejaria belga Interbrew, em 2004. (PROENÇA, 2005)

\subsection{Legislação sobre insider trading no Brasil}

A legislação brasileira que trata da prática de insider trading existe desde 1965. A Lei 4728, artigo 3, delegou ao Banco Central a competência para "fiscalizar a utilização de informações não divulgadas ao público em benefício próprio ou de terceiros, por acionistas ou pessoas que, por força dos cargos que exerçam, a elas tenham acesso", não estabelecendo de forma efetiva uma fiscalização e nem determinando, diretamente, a proibição de Insider trading. A Resolução 88 dispõe que as empresas, ao se registrarem no Banco Central (BC), deveriam assumir compromisso formal de revelar prontamente ao público as decisões tomadas pela Diretoria e pela Assembleia Geral em relação a dividendos, a direitos de subscrição ou a outros elementos que pudessem afetar os preços dos títulos ou valores mobiliários de sua emissão ou influenciar as decisões dos investidores. (AGRIZZI, 1989)

Em 1969, a economia brasileira apresentou grande e seguido crescimento do PIB (Produto Interno Bruto), acompanhado da redução da taxa inflacionária. Consequentemente, foram estabelecidas medidas de caráter administrativo, tomadas no sentido de tornar mais ampla a fiscalização do BC. No mesmo ano, as bolsas de valores de todo o país apresentavam aumentos significativos do volume dos negócios e no índice de rentabilidade. O conjunto de medidas adotado pelo governo obteve significado positivo no período de 1970/71, quando houve os efeitos iniciais dos incentivos do Decreto-Lei 157, concretizando uma rápida e contínua alta dos preços e das cotações das ações, além de um aumento do volume negociado nos pregões e balcões.

Em maio de 1971, o mercado apresentou uma fase depressiva por alguns anos. Apesar de todas as medidas legais existentes, foram constatadas diversas fraudes praticadas por administradores e controladores das empresas (AGRIZZI, 1989). Mesmo com os incentivos fiscais que foram tomados, no período de 1974 a 1976, tais medidas só serviram como paliativos.

Com a preocupação de proteger os investidores minoritários em 1976, foi aprovada a Lei 6404/76, que reformulou a relação entre os investidores e o mercado de ações, tornando obrigatória a existência de um Conselho de Administração, e foram completamente reformuladas as condições de funcionamento dessas sociedades, enfatizando-se a relação entre os investidores e o mercado de ações. Dentro desse propósito, estabeleceram-se novas regras de comportamento da sociedade, de seus acionistas controladores e de seus administradores, na tentativa de conscientizá-los de seus deveres e responsabilidades e de reeducá-los, segundo princípios éticos, de forma a serem evitadas manipulações. (AGRIZZI, 1989)

No que se refere a casos de insider trading, a lei 6404/76 incorporou sua proibição, quando mencionou o dever de guardar sigilo sobre qualquer informação que ainda não tenha sido divulgada para o mercado, obtida em razão do cargo e capaz de influir no comportamento das cotações de valores mobiliários, para si ou para outrem 
vantagem mediante a compra e venda de ações no mercado de capitais brasileiro.

Pelo exposto, no Brasil, há grande preocupação diante ao tema de insider trading, que tem objeto de maior monitoramento da CVM, autarquia vinculada ao Ministério da Fazendo do Brasil. A Lei que criou a CVM (6385/76) e a Lei das Sociedades por Ações (6404/76) diz o foco é: "Disciplinar o funcionamento do mercado de valores mobiliários e a atuação de seus protagonistas, assim classificados, as companhias abertas, os intermediários financeiros e os investidores, além de outros cuja atividade gira em torno desse universo principal”.

A CVM tem poderes para disciplinar, normatizar e fiscalizar a atuação dos diversos integrantes do mercado. Seu poder normatizador abrange todas as matérias referentes ao mercado de valores mobiliários. Com isso, existe uma grande preocupação da CVM para definir insider trading. Nos termos da Lei no 6.404/76, "insider trading é qualquer operação realizada por um insider com valores mobiliários de emissão da companhia, e em proveito próprio, pessoal".

Convém que se esclareça, desde logo, que não é ilícita, em princípio, uma operação assim realizada pelo insider. Somente quando a operação se revestir de determinadas características, é que se constituirá ela um ato ilícito. Quanto a essa caracterização, bem como aos critérios de penalização de seus participantes, as legislações dos países adotam os mais diversos princípios. No Brasil, de acordo com CVM (2013), a prática de insider trading acarretará a instauração de um Inquérito Administrativo. A CVM, por ora, uma vez que não há regulamentação específica, poderá instaurar esse inquérito administrativo contra os administradores (diretores e membros do conselho de administração), membros de órgãos, criados pelo estatuto, com funções técnicas ou consultivas e membros do conselho fiscal.

Constatada a infração, a CVM aplicará aos infratores as seguintes penalidades: advertência; multa; suspensão do exercício do cargo de administrador de companhia aberta ou de entidade do sistema de distribuição de valores; inabilitação para exercício dos cargos referidos no parágrafo anterior; suspensão da autorização ou registro para o exercício das atividades de que trata a Lei $n^{\circ} 6.385 / 76$ e cassação da autorização ou registro indicado na alínea anterior. Salienta-se que, no momento, só são aplicáveis as duas primeiras penalidades (advertência e multa), já que as demais só o são em caso de infrações graves, assim definidas pela CVM, e em casos de reincidência.

\subsection{Penalidades para a prática de insider trading}

Em termos judiciais, o prejudicado poderá propor ação civil ou ação criminal (CVM, 2015). As ações civis podem ser contempladas por:

a) ação civil contra administradores - conselheiros e diretores, membros de órgãos consultivos e técnicos criados pelo estatuto e conselheiros fiscais, para haver indenização por perdas e danos, em conformidade com o art. 155 da Lei $n^{\circ} 6.404 / 76$;

b) ação civil, para haver perdas e danos, contra quem lhe causou o prejuízo, na forma do art. 159 do Código Civil ou;

c) ação civil para anular a operação, contra quem omitiu dolosamente informações relevantes, no momento da realização da operação (artigos 92 e 94 do Código Civil).

Em termos criminais, a CVM, depois de concluído o inquérito e de constatado o crime de ação pública, no caso estelionato, deverá oficiar ao Ministério Público para a propositada da ação penal. Em termos de prova do insider trading, os indícios são elementos da maior relevância para a sua constatação, sendo por meio deles que se presumirá a ocorrência da operação. Deve ser reforçado o aspecto de que, somente com base em indícios que conduzem a presunções, a CVM e os juízes poderão concluir ter havido insider trading e, consequentemente, julgar e legitimamente penalizar os infratores. Vale ressaltar, entretanto, que as decisões da CVM não são definitivas, sendo passíveis de apreciação pelo Poder Judiciário. 


\section{DESIGN DA PESQUISA E DESCRIÇÃO DOS DADOS}

Para que fosse possível investigar se existe relação entre o volume de transações de compra e venda de ações da companhia conduzidas por insiders e o seu valor de mercado e/ou rentabilidade nas empresas brasileiras, utilizou-se dados trimestrais das 100 empresas mais líquidas listadas na BM\&FBovespa e com registro ativo na CVM. Como proxy para o volume de transações efetuado por insiders (Técnico Executivo, Diretores, Conselheiros Fiscais, Conselheiros Administrativos e Acionista Controlador), utilizou-se o valor das movimentações de compra e venda de ações por parte desses agentes.

A seleção da amostra utilizada neste estudo considera a disponibilização de dados não estruturados enviados pelas empresas à Comissão de Valores Mobiliários e dados obtidos no sistema Economática® para o período entre o primeiro trimestre de 2007 e o último trimestre de 2011. No site da CVM foram obtidas as informações do volume transacionado por insiders que constam no Sistema de Envio de Informações Periódicas e Eventuais (IPE), um sistema desenvolvido conjuntamente com a BM\&FBovespa no intuito de facilitar o cumprimento das regras pelas companhias. No Economática ${ }^{\circledR}$ foram coletados informações referentes às demais variáveis utilizadas: receita bruta (Rec), dívida bruta (Dívida), despesas com vendas e administrativas (DVendas), média trimestral do preço de fechamento diário por ação (VMTrim), rentabilidade (ROA), volume transacionado de ações (Vol) e ativo total (At). Quando necessário consideramos as cotações ajustadas por proventos (dividendos, desdobramentos e bonificações).

A partir do trabalho desenvolvido por Gunny, Ke e Zhang (2009), foram elaborados dois modelos para que fosse possível verificar a relação entre o volume de transações insider trading e: a rentabilidade (Hipótese 1); o valor de mercado da empresa (Hipótese 2). As equações que representam cada um dos dois modelos propostos estão expostas a seguir:

$$
\begin{aligned}
& \text { ROA }_{\mathrm{it}+1}=\beta_{0}+\beta_{1} \text { Compra }_{\mathrm{it}}+\beta_{2} \text { Insider }_{\mathrm{it}}+\beta_{3} \text { Compra }_{\mathrm{it}} \text { Insider }_{\mathrm{it}}+\beta_{4} \text { Insider }_{\mathrm{it}}+ \\
& +\beta_{5} \operatorname{Rec}_{\mathrm{it}}+\beta_{6} \text { Dívida }_{\mathrm{it}}+\beta_{7} \text { DVendas }_{\mathrm{it}}+\beta_{8} \text { Tamanho }_{\mathrm{it}}+\varepsilon_{\mathrm{it}} \\
& \text { VMTrim }_{\mathrm{it}+1}=\beta_{0}+\beta_{1} \text { Compra }_{\mathrm{it}}+\beta_{2} \text { Insider }_{\mathrm{it}}+\beta_{3} \text { Compra }_{\mathrm{it}} \text { Insider }_{\mathrm{it}}+\beta_{4} \text { Insider }_{\mathrm{it}} \\
& +\beta_{5} \operatorname{Rec}_{\mathrm{it}}+\beta_{6} \text { Dívida }_{\mathrm{it}}+\beta_{7} \text { DVendas }_{\mathrm{it}}+\beta_{8} \text { Tamanho }_{\mathrm{it}}+\varepsilon_{\mathrm{it}}
\end{aligned}
$$

Nos modelos 1 e 2, Tamanho representa o logaritmo do ativo total, Insider representa a razão entre o volume total de transações efetuadas por insiders e o volume total de transações da empresa no trimestre, Compra é uma variável dummy que assume valor igual a 1 se as transações líquidas de insiders são positivas (posições compradas), e 0 caso contrário, e ROA é dado pelo Ebit sobre o ativo total do ano anterior (WENERCK et al., 2010). As variáveis receita bruta, dívida bruta e despesa com vendas e administrativas foram todas padronizadas pelo ativo total do ano anterior de forma a permitir comparabilidade.

Como as transações de insider trading podem estar associadas à insiders que ocupam diversas posições na empresa, tais como o conselheiro de administração (ConsAdm), o conselheiro fiscal (ConsFis), o acionista controlador (Contr), o técnico executivo (TecEx) ou diretores (Dir.), a variável Insider foi segregada de forma que fosse possível identificar uma possível relação entre as transações efetuadas por cada um dos agentes econômicos citados e variações tanto da rentabilidade quanto do valor médio das empresas. Nesses casos, formulou-se os modelos 3 e 4, os quais estão apresentados a seguir:

$$
\begin{aligned}
\text { ROA }_{i t+1}=\beta_{0}+ & \beta_{1} \text { ConsAdm }_{i t}+\beta_{2} \text { ConsFis }_{i t}+\beta_{3} \operatorname{Contr}_{i t}+\beta_{4} \operatorname{TecEx}_{\mathrm{it}}+\beta_{5} \operatorname{Dir}_{\mathrm{it}}+\beta_{6} \operatorname{Rec}_{\mathrm{it}} \\
+ & \beta_{7} \text { Dívida }_{\mathrm{it}}+\beta_{8} \text { DVendas }_{\mathrm{it}}+\beta_{9} \text { Tamanho }_{\mathrm{it}}+\varepsilon_{\mathrm{it}} \\
\text { VMTrim }_{\mathrm{it}+1}= & \beta_{0}+\beta_{1} \text { ConsAdm }_{\mathrm{it}}+\beta_{2} \text { ConsFis }_{\mathrm{it}}+\beta_{3} \text { Cont }_{\mathrm{it}}+\beta_{4} \operatorname{TecEx}_{\mathrm{it}}+\beta_{5} \operatorname{Dir}_{\mathrm{it}} \\
& +\beta_{6} \operatorname{Rec}_{\mathrm{it}}+\beta_{7} \text { Dívida }_{\mathrm{it}}+\beta_{8} \text { DVendas }_{\mathrm{it}}+\beta_{9} \operatorname{Tamanho}_{\mathrm{it}}+\varepsilon_{\mathrm{it}}
\end{aligned}
$$




\section{RESULTADOS}

A Tabela 1 apresenta a estatística descritiva das variáveis utilizadas neste trabalho. Observa-se que as transações por insider representam em média 3\% do volume total transacionado no período analisado, com máxima de 99\%. Tais resultados indicam que o volume negociado por insiders representa uma fatia significativa do volume total transacionado dentre as empresas mais líquidas do mercado brasileiro. A máxima de $99 \%$ do total transacionado sugere ainda que quase a totalidade das transações de uma determinada empresa em um trimestre específico foi realizado por algum insider dessa empresa.

Os resultados da Tabela 1 mostram ainda que os membros dos conselhos discal e de administração e o acionista controlador são os que mais realizam transações dentre o total de volume transacionado por insiders. Tais resultados seguem alinhados à expectativa de que as operações dos insiders têm potencial para antecipar alterações futuras da rentabilidade das empresas, principalmente em mercados com alta concentração acionária e nos quais o conselho de administração participa ativamente da aprovação de decisões estratégicas, como é o caso do Brasil.

O gráfico 1 permite uma melhor visualização do máximo volume transacionado por parte de cada um dos insiders em relação ao total transacionado. Membros da diretoria, embora apresentem máximas inferiores às obtidas pelos membros dos conselhos fiscal e de administração e pelo acionista controlador, ainda se mostram por vezes com participações significativas, com máxima que ultrapassa a casa dos 40 por cento da totalidade dos ativos negociados por determinada empresa.

Tabela 1. Estatística descritiva

\begin{tabular}{lccccc}
\hline \multicolumn{1}{c}{ Variável } & Obs. & Média & $\begin{array}{c}\text { Desvio- } \\
\text { padrão }\end{array}$ & Mín. & Máx. \\
\hline Retorno sobre Ativos & 1760 & 1,51 & 3,82 & $-63,39$ & 42,38 \\
$\begin{array}{l}\text { Média Trimestral do } \\
\text { Valor por Ação }\end{array}$ & 1733 & 14,98 & 12,97 & 0,00 & 113,17 \\
Transações por Insider / Volume & & & & & \\
Transacionado & 1858 & 0,03 & 0,11 & 0,00 & 0,99 \\
Total & 1858 & 0,01 & 0,06 & 0,00 & 0,99 \\
$\quad 1858$ & 0,00 & 0,02 & 0,00 & 0,46 \\
$\quad$ Conselho Adm. & 1858 & 0,00 & 0,05 & 0,00 & 0,98 \\
$\quad$ Diretoria & 1858 & 0,02 & 0,07 & 0,00 & 0,85 \\
$\quad$ Conselho Fiscal & 1858 & 0,00 & 0,00 & 0,00 & 0,15 \\
$\quad$ Técionista Controlador & 1850 & 22,18 & 1,73 & 16,49 & 27,60 \\
$\quad 1683$ & 0,19 & 0,13 & 0,00 & 1,12 \\
Tamanho (ln do Ativo Total) & 1683 & 0,02 & 0,03 & 0,00 & 0,27 \\
Receita Bruta / Ativo total & 1694 & 0,00 & 0,00 & 0,00 & 0,00 \\
Desp. Vendas / Ativo Total & 1858 & 61395 & 8741 & 39993 & 71897 \\
Dívida / Ativo Total & & & &
\end{tabular}

Fonte: Elaboração Própria 


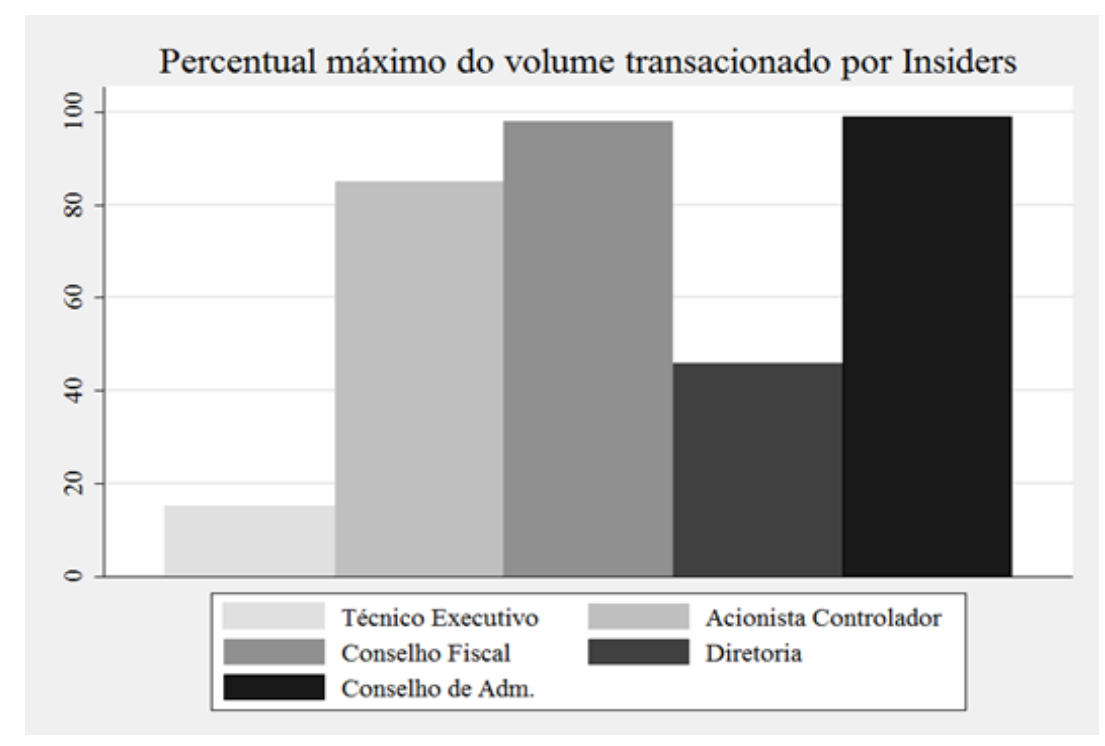

Gráfico 1. Elaborado pelos autores

A Tabela 2 apresenta as correlações entre as variáveis estudadas. Note que, embora a rentabilidade não seja correlacionada com o volume total líquido transacionado por insiders, o ROA é negativamente correlacionada com as transações líquidas efetuadas por membros do conselho de administração e pelo acionista controlador. Tais resultados vão de encontro à hipótese de que posições compradas de insiders estão associadas em média à um aumento da rentabilidade das empresas e sugerem inicialmente uma associação negativa entre operações de membros do conselho e o acionista majoritário e a rentabilidade das empresas.

Tal associação negativa foi também encontrada por Budsaratragoon et al. (2012), os quais sugerem que as transações líquidas de insiders corporativos de países emergentes como a Thailandia estão na direção oposta à performance anormal do mercado, o que sugere que performances anormais positivas do mercado em um determinado período estão associadas em média à posições vendidas de insiders.

Os resultados com relação à associação entre as transações feitas pelos membros da diretoria e a rentabilidade, entretanto, vão ao encontro da hipótese H1, assim como a correlação negativa entre a média trimestral do preço por ação e as transações líquidas efetuadas por membros do conselho de administração vai ao encontro da hipótese H2. No geral, tais evidências suportam a teoria de Grossman e Stiglitz (1980), os quais demonstram que transações dos insiders, ao sinalizarem movimentações das expectativas de alteração do lucro futuro, adicionam informatividade ao sistema de precificação das ações (Girão, Martins e Paulo, 2015). 
Tabela 2. Tabela de correlação (Correlação de Spearmann)

\begin{tabular}{|c|c|c|c|c|c|c|c|c|c|c|c|c|}
\hline & $\begin{array}{l}\text { Retorno } \\
\text { sobre ativos }\end{array}$ & $\begin{array}{c}\text { Média } \\
\text { Trimestral } \\
\text { do Valor } \\
\text { por Ação }\end{array}$ & $\begin{array}{l}\text { Conselho } \\
\text { Adm }\end{array}$ & Diretoria & $\begin{array}{l}\text { Conselho } \\
\text { Fiscal }\end{array}$ & $\begin{array}{l}\text { Acionista } \\
\text { Controlador }\end{array}$ & $\begin{array}{l}\text { Técnico } \\
\text { Executivo }\end{array}$ & Total & Tamanho & $\begin{array}{c}\text { Receita / } \\
\text { Bruta Ativo } \\
\text { Total }\end{array}$ & $\begin{array}{c}\text { Desp } \\
\text { Vendas / } \\
\text { Receita } \\
\text { Bruta }\end{array}$ & $\begin{array}{c}\text { Dívida / } \\
\text { Ativo Total }\end{array}$ \\
\hline Retorno sobre ativos & -1 & & & & & & & & & & & \\
\hline $\begin{array}{l}\text { Média Trimestral do } \\
\text { Valor por Ação }\end{array}$ & $0,132 * * *$ & 1 & & & & & & & & & & \\
\hline Conselho Adm & $-0,050 * *$ & $-0,155 * *$ & 1 & & & & & & & & & \\
\hline Diretoria & $0,152 * * *$ & $-0,018$ & $0,245 * * *$ & 1 & & & & & & & & \\
\hline Conselho Fiscal & $-0,011$ & $-0,037$ & 0,028 & $-0,015$ & 1 & & & & & & & \\
\hline Acionista Controlador & $-0,052 * *$ & 0,01 & 0,031 & $0,127 * *$ & $0,127 * *$ & 1 & & & & & & \\
\hline Técnico Executivo & 0,014 & 0,033 & 0,041 & $0,104 * * *$ & $0,135 * * *$ & $0,106 * * *$ & 1 & & & & & \\
\hline Total & $-0,022$ & $-0,145 * * *$ & $0,563 * * *$ & $0,537 * * *$ & $0,144 * * *$ & $0,569 * * *$ & $0,129 * * *$ & 1 & & & & \\
\hline Tamanho & $-0,048^{*}$ & $0,354 * * *$ & $-0,091 * * *$ & $-0,108 * * *$ & $0,171^{* * *}$ & 0,010 & $0,136^{* * *}$ & $-0,159 * * *$ & 1 & & & \\
\hline $\begin{array}{l}\text { Receita Bruta / Ativo } \\
\text { Total }\end{array}$ & $0,239 * * *$ & 0,011 & $0,07 * * *$ & $0,138 * * *$ & $-0,021$ & $-0,084 * * *$ & 0,035 & $0,096 * * *$ & $-0,329 * *$ & 1 & & \\
\hline $\begin{array}{l}\text { Desp Vendas / Receita } \\
\text { Bruta }\end{array}$ & $0,159 * * *$ & 0,001 & $0,060^{* *}$ & $0,180 * * *$ & $-0,070 * * *$ & $-0,072 * * *$ & $-0,090 * * *$ & $-0,089 * * *$ & $-0,261 * * *$ & $-0,584 * * *$ & 1 & \\
\hline Dívida Ativo / Total & $-0,278 * * *$ & $-0,001$ & 0,024 & $-0,018$ & $-0,014$ & $0,043 *$ & $0,056^{* *}$ & 0,006 & $0,094 * * *$ & $-0,025$ & $-0,035$ & 1 \\
\hline
\end{tabular}

Retorno sobre ativos (ROA) representa o lucro operacional (EBIT) dividido pelo ativo total; Média trimestral do valor da ação representa a média da cotação diária da ação em cada trimestre; Conselho de Adm. representa o volume financeiro negociado por membros do conselho de administração de cada empresa no trimestre; Diretoria representa o volume financeiro negociado por membros da diretoria de cada empresa no trimestre; Conselho Fiscal representa o volume financeiro negociado por membros do conselho fiscal de cada empresa no trimestre; Acionista controlador representa o volume financeiro negociado pelos acionistas controladores de cada empresa no trimestre; Técnico executivo representa o volume financeiro negociado por membros do comitê técnicoexecutivo de cada empresa (quando for o caso) no trimestre; Total representa a soma do volume financeiro negociado pelo conselho de administração, diretoria, acionista controlador, conselho fiscal e técnico executivo de cada empresa no trimestre; Tamanho representa o logaritmo do ativo total. As variáveis receita bruta, dívida bruta e despesa com vendas e administrativas foram todas padronizadas pelo ativo total do ano anterior de forma a permitir comparabilidade. Os símbolos ***, ** e * correspondem a 1\%, 5\% e $10 \%$ de significância estatística, respectivamente. O teste de rho-spearman mostra se a correlação era estatisticamente significante entre as variáveis. 
Tabela 3. Resultado da estimação dos modelos 1 e 2 com regressões em painel com efeito fixo

\begin{tabular}{|c|c|c|c|}
\hline & Variável Dependente: & $\begin{array}{l}\text { Retorno sobre Ativo } \\
\qquad(\mathrm{n}=\mathbf{5 8 2})\end{array}$ & $\begin{array}{l}\text { Média Trimestral do } \\
\text { Preço por Ação } \\
(\mathrm{n}=721)\end{array}$ \\
\hline \multirow{13}{*}{ 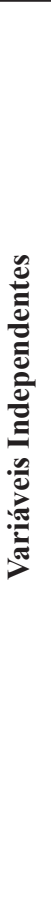 } & Dummy Compra por Insiders & $\begin{array}{c}0,003 \\
(0,154)\end{array}$ & $\begin{array}{c}0,691 * * * \\
(0,001)\end{array}$ \\
\hline & Transações por Insider & $\begin{array}{c}0,000 \\
(0,173)\end{array}$ & $\begin{array}{c}0.000 \\
(0.996)\end{array}$ \\
\hline & $\begin{array}{c}\text { Dummy Compra x Transações } \\
\text { por Insiders }\end{array}$ & $\begin{array}{c}0,000 \\
(0,394)\end{array}$ & $\begin{array}{c}0,000 \\
(0,556)\end{array}$ \\
\hline & Tamanho & $\begin{array}{c}0,002 \\
(0,467)\end{array}$ & $\begin{array}{c}-0,843 * * * \\
(0,003)\end{array}$ \\
\hline & & $0,080^{* * *}$ & $2,833 *$ \\
\hline & Receita / Ativo Total & $(0,000)$ & $(0,092)$ \\
\hline & Desn Vendas / Ative Total & $-0,156$ & $-28,347 * * *$ \\
\hline & Desp. vendas / Ativo rotal & $(0,114)$ & $(0,006)$ \\
\hline & Dívide L tivo Tatol & $-0,070 * * *$ & $-5,149 * * *$ \\
\hline & Diviaa / Ativo lotal & $(0,000)$ & $(0,000)$ \\
\hline & Jbovesna & $-0,016$ & $2,062 * * *$ \\
\hline & 100vespa & & \\
\hline & Constante & $\begin{array}{l}-0,012 \\
(0,862)\end{array}$ & $\begin{array}{c}24,262 * * * \\
(0,000)\end{array}$ \\
\hline
\end{tabular}

Notas: $* * *, * * \mathrm{e} *$ correspondem a 1\%,5\% e 10\% de significância, respectivamente. Os p-valores estão entre parênteses.

Retorno sobre ativos representa o lucro operacional (EBIT) dividido pelo ativo total; Média trimestral do valor da ação representa a média da cotação diária da ação em cada trimestre; Transações por Insider representa a razão entre o volume total de transações efetuadas por insiders e o volume total de transações da empresa no trimestre, onde o volume total de transações representa a soma do volume financeiro negociado pelo conselho de administração, diretoria, acionista controlador, conselho fiscal e técnico executivo de cada empresa no trimestre; Compra por Insiders é uma variável dummy que assume valor igual a 1 se as transações líquidas de insiders são positivas (posições compradas), e 0 caso contrário; tamanho representa o logaritmo do ativo total; Tamanho representa o logaritmo do ativo total. As variáveis de controle receita, dívida e despesa com vendas e administrativas foram padronizadas pelo ativo total do ano anterior. Ibovespa representa o retorno do Ibovespa no trimestre.

Fonte: Elaboração Própria

Os resultados da regressão para os modelos 1 e 2 seguem dispostos na Tabela 3. Os resultados do modelo 1 sugerem que variações do percentual de transações insider com relação ao total transacionado não têm efeito na rentabilidade da empresa. O coeficiente da dummy que diferencia posições compradas de posições vendidas também não se mostrou estatisticamente significante. Conjuntamente, tais resultados não suportam a hipótese H1 de que posições compradas de insiders estão associadas em média à um aumento da rentabilidade. Nesse caso, os resultados sugerem que no mercado brasileiro as transações de insiders não sinalizam em média antecipação de alterações do lucro das empresas.

Os resultados do modelo 2, entretanto, apresentam indícios de que, embora o volume transacionado não apresente efeito significativo no preço das ações, a posição comprada por parte dos insiders está positivamente associada à um aumento do valor de mercado das empresas, o que suporta a hipótese H2. Tais evidências estão alinhadas aos resultados obtidos por Gunny, Ke, Zhang (2009), Bebchuk e Cohen (2005) e Bebchuk e Weisbach (2010), os quais sugerem que a manutenção da posição comprada por parte dos insiders por um maior período de tempo ou o aumento de tal posição aumentam as probabilidades da obtenção de retornos positivos.

Como forma de verificar se transações de insiders que possuem posições específicas na empresa (conselheiro de administração, conselheiro fiscal, acionista controlador, técnico executivo e diretores) afetam a rentabilidade e/ou valor da empresa, a Tabela 4 apresenta os resultados das estimações dos modelos 3 e 4, nos quais 
a variável Insider foi segregada de forma a considerar as transações líquidas de cada um dos agentes econômicos citados.

\begin{tabular}{|c|c|c|c|c|}
\hline & & Variável dependente: & $\begin{array}{l}\text { Retorno sobre Ativo } \\
\quad(\mathrm{n}=\mathbf{5 8 2})\end{array}$ & $\begin{array}{l}\text { Média Trimestral do } \\
\text { Valor por Ação } \\
(\mathrm{n}=721)\end{array}$ \\
\hline \multirow{20}{*}{ 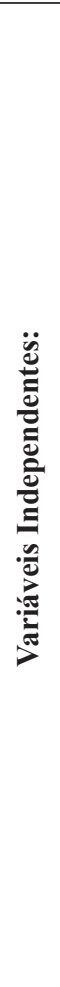 } & \multirow{10}{*}{ 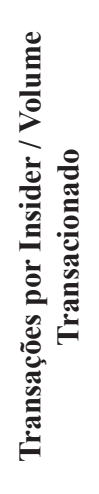 } & \multirow{2}{*}{ Conselheiro Adm. } & -1.016 & -2.9533 \\
\hline & & & $(2.0727)$ & $(4.0509)$ \\
\hline & & \multirow{2}{*}{ Diretoria } & -0.5278 & -13.1639 \\
\hline & & & 4.388 & $(8.5615)$ \\
\hline & & \multirow{2}{*}{ Conselheiro Fiscal } & -23.1374 & $-168,2653$ \\
\hline & & & $(26.3644)$ & $(175.1657)$ \\
\hline & & \multirow{2}{*}{ Acionista Controlador } & 0.6234 & -3.7392 \\
\hline & & & $(1.2641)$ & $(2.47)$ \\
\hline & & \multirow{2}{*}{ Técnico Executivo } & 1.0214 & -5.1906 \\
\hline & & & $(20.0894)$ & $(39.0082)$ \\
\hline & \multirow{10}{*}{$\frac{0}{\stackrel{0}{0}}$} & \multirow{2}{*}{ Tamanho } & 0.027 & $2.2244 * * *$ \\
\hline & & & $(0.2638)$ & $(0.5143)$ \\
\hline & & \multirow{2}{*}{ Receita / Ativo Total } & $4.6645 * * *$ & $8.1204 * *$ \\
\hline & & & $(1.7541)$ & $(3.4274)$ \\
\hline & & \multirow{2}{*}{ Desp. Vendas / Ativo Total } & $-58.1563 * * *$ & -32.244 \\
\hline & & & $(11.0647)$ & $(21.645)$ \\
\hline & & \multirow{2}{*}{ Dívida / Ativo Total } & $-6794.799 * * *$ & $-9554.957 * * *$ \\
\hline & & & (1135.016) & (2211.027) \\
\hline & & \multirow{2}{*}{ Constante } & 3.2507 & $-32.04811 * * *$ \\
\hline & & & $(5.8692)$ & $(11.4544)$ \\
\hline
\end{tabular}

Notas: $* * *, * * \mathrm{e} *$ correspondem a $1 \%, 5 \%$ e $10 \%$ de significância, respectivamente. Desvios-padrão estão entre parênteses.

Retorno sobre ativos representa o lucro operacional (EBIT) dividido pelo ativo total; Média trimestral do valor da ação representa a média da cotação diária da ação em cada trimestre; Conselho de Adm. representa o volume financeiro negociado por membros do conselho de administração de cada empresa no trimestre dividido pelo ativo total; Diretoria representa o volume financeiro negociado por membros da diretoria de cada empresa no trimestre dividido pelo ativo total; Conselho Fiscal representa o volume financeiro negociado por membros do conselho fiscal de cada empresa no trimestre dividido pelo ativo total; Acionista controlador representa o volume financeiro negociado pelos acionistas controladores de cada empresa no trimestre dividido pelo ativo total; Técnico executivo representa o volume financeiro negociado por membros do comitê técnico-executivo de cada empresa (quando for o caso) no trimestre dividido pelo ativo total; tamanho representa o logaritmo do ativo total; Tamanho representa o logaritmo do ativo total. As variáveis de controle receita, dívida e despesa com vendas e administrativas foram padronizadas pelo ativo total do ano anterior. Ibovespa representa o retorno do Ibovespa no trimestre.

Fonte: Elaboração Própria

As estimativas dos coeficientes das transações realizadas por cada um dos agentes analisados não foram estatisticamente significativas em nenhum dos modelos, o que sugere que não se pode afirmar a existência de um comportamento sistemático de efeito tanto na rentabilidade quanto no valor das empresas por transações realizadas por agentes isolados.

Girão, Martins e Paulo (2015) afirmam transações de insiders são relevantes para as decisões de investimentos e que a tempestividade das transações exerce influência em tais decisões. Os resultados apresentados acima, entretanto, sugerem que transações isoladas não possuem sistematicamente potencial para antecipar alterações de rentabilidade e valor das empresas. Nesse caso, a contraposição de transações efetuadas pelos diferentes tipos de insiders se mostram necessárias para que negociações anormais sejam levadas em consideração 
nas decisões de investimentos dos demais acionistas.

Tais resultados suportam ainda Telder (2011), que afirma que uma maior clareza e controle da divulgação das informações pode evitar o favorecimento de determinados grupos e reduzir a assimetria informacional existente entre gestores e stakeholders. Com base nos resultados obtidos, um maior rigor com relação à divulgação das informações pode contribuir para que seja minimizado o potencial impacto negativo dessas condutas na variação do preço das ações e no valor das empresas brasileiras.

\section{CONCLUSÃO}

Este trabalho utilizou informações da base de dados Economatica ${ }^{\circledR}$ e de dados não estruturados enviados pelas empresas listadas na BM\&FBovespa à Comissão de Valores Mobiliários para o período entre o primeiro trimestre de 2007 e o último trimestre de 2011 para que fosse possível investigar se existe relação entre o volume de transações de compra e venda de ações da companhia conduzidas por insiders e o seu valor de mercado e/ou rentabilidade. Como proxy para o volume de transações efetuado por insiders (Técnico Executivo, Diretores, Conselheiros Fiscais, Conselheiros Administrativos e Acionista Controlador) utilizou-se o valor das movimentações de compra e venda de ações por parte desses agentes.

No site da CVM foram obtidas as informações do volume transacionado por insiders que constam no Sistema de Envio de Informações Periódicas e Eventuais (IPE), um sistema desenvolvido conjuntamente com a BM\&FBovespa no intuito de facilitar o cumprimento das regras pelas companhias. No Economática ${ }^{\circledR}$ foram coletados indicadores financeiros e outras informações como receita, ativo total, despesas com vendas e administrativas, média trimestral do valor por ação, rentabilidade, volume transacionado de ações e dívida bruta.

Os resultados obtidos, embora indiquem que não há indícios de relação significativa do volume de transações realizados por insiders tanto no preço quanto na rentabilidade da empresa, sugerem que existe um efeito positivo entre posições compradas assumidas por insiders e a média trimestral do valor de mercado. Tais resultados sugerem que, independente do valor transacionado, posições compradas por parte dos insiders tem potencial para sinalizar aumentos do valor de mercado das empresas brasileiras.

Esta relação positiva entre a média trimestral do preço por ação e o percentual de transações insider com relação ao total transacionado pode indicar que os insiders atuam principalmente quando há indícios de que a organização está prestes a apresentar boas notícia para o mercado de capitais, notícia esta que poderá gerar um aumento no valor das ações. Com relação à rentabilidade, entretanto, variações do percentual de transações insider com relação ao total transacionado não apresentaram relação estatisticamente significativa com variações de rentabilidade das empresas

Como as transações de insider trading podem estar associadas à insiders que ocupam diversas posições na empresa como conselheiro de administração, conselheiro fiscal, acionista controlador, técnico executivo ou diretores, o percentual de transações realizado por insiders foi segregada de forma que fosse possível identificar os efeitos na rentabilidade e valor de transações efetuadas por cada um desses agentes econômicos. As estimativas dos coeficientes das transações realizadas por cada um dos agentes analisados não foram estatisticamente significativas, o que sugere que não se pode afirmar a existência de um comportamento sistemático de efeito tanto na rentabilidade quanto no valor das empresas por transações realizadas por agentes isolados. Este resultado está em linha com os resultados encontrados por Gunny, Ke, Zhang (2009), Bebchuk e Cohen (2005) e Bebchuk e Weisbach (2010).

Segundo Telder (2011), uma maior clareza e controle da divulgação das informações pode evitar o favorecimento de determinados grupos e reduzir a assimetria informacional existente entre gestores e stakeholders. Com base nos resultados obtidos, um maior rigor com relação à divulgação das informações pode contribuir para que seja minimizado o potencial impacto negativo dessas condutas na variação do preço das ações e no valor das empresas brasileiras. 


\section{REFERÊNCIAS}

AGRIZZI, D. A. Uma análise comparada das experiências de regulação do mercado de capitais: os casos do Brasil, Inglaterra, Estados Unidos, França e Japão. 1989. Dissertação (Mestrado) - Fundação Getúlio Vargas, São Paulo, 1989.

AIER, J. K. Insider trading in loss firms. Advances in Accounting, v. 29, n. 1, p. 12-26, 2013.

AKERLOF, G. A. The Market for "Lemons": Quality, uncertainty and the market mechanism. Quarterly Journal of Economics, v. 84, n. 3, p. 488-500, 1970.

AKTAS, Nihat; DE BODT, Eric; VAN OPPENS, Hervé. Legal insider trading and market efficiency. Journal of Banking \& Finance, v. 32, n. 7, p. 1379-1392, 2008.

ASSAF NETO, A. Finanças corporativas e valor. São Paulo: Atlas, 2003.

ASSESSORIA de Comunicação da Procuradoria da República de São Paulo 11-3269-5068. Denúncia pelo MPF/ SP do primeiro caso de insider trading no País. Disponível em: < http://noticias.pgr.mpf.mp.br/noticias/ noticias-do-site/copy_of criminal/06-05-09-mpf-sp-oferece-primeira-denuncia-de-insider-trading-nobrasil/>. Acesso em: 03 ago. 2013.

ASSOCIAÇÃO BRASILEIRA DE NORMAS TÉCNICAS. Informação e documentação - apresentação de citações em documentos: NBR 10520. Rio de Janeiro, 2002.

BAGEHOT, W. Lombard Street: a description of the money market. New York: John Wiley e Sons, 1999.

BALL, R.; BROWN, P. An empirical evaluation of accounting income numbers. Journal of Accounting Research, v.6, n. 2, 1968.

BARTH, M.; BEAVER, W.; LANDSMAN, W. The Relevance of the Value Relevance Literature for Financioal Accounting Standard Setting: Another View. JAE Rochester Conference April 2000, 2001.

BEAVER, W. The information content of annual earnings announcements. Journal of Accounting Research, v. $6,1968$.

BEBCHUK, L. A.; COHEN, A. The costs of entrenched boards. Journal of Financial Economics, v. 78, n. 2, p. 409-433, 2005.

; WEISBACH, M. S. The state of corporate governance research. Review of Financial Studies, v. 23, n. 3, p. 939-961, 2010.

BENY, L.N. A comparative empirical investigation of agency and Market theories of insider trading. 2004.

BMeFBOVESPA. Descrição da variável Retorno Bovespa. Disponível em: < $\underline{\text { http://www.bmfbovespa.com.br/ }}$ indices/ResumoIndice.aspx? Indice=IBOVESPAeIdioma=pt-BR $>$. Acesso em 20 jul. 2013.

Classificação Setorial das Empresas. Disponível em: < http://www.bmfbovespa.com.br/Cias-Listadas/ consultas/classificacao-setorial.aspx?idioma=pt-br>. Acesso em: 20 jul. 2013.

BOWEN, R. M.; RAJGOPAL, S.; VENKATACHALAM, M. Accounting Discretion, Corporate Governance, and Firm Performance. Contemporary Accounting Research, v. 25, n. 2, p. 351-405, 2008.

BRIGHAM, E. F.; EHRHARDT, M. C. Administração financeira: teoria e prática. São Paulo: Atlas, 2008.

CASO de Insider Trading na Gol. Disponível em: < $\underline{\text { http://www.cvm.gov.br/port/inqueritos/2011/rordinario/ }}$ inqueritos/IA\%2019-09\%20GOL.asp>. Acesso em: 29 jul. 2013.

CERVO, A.L.; BERVIAN, P. A.; SILVA, R. Metodologia científica. 6. ed. São Paulo: Pearson Prentice Hall, 2007.

COMISSÃO de Valores Mobiliários-CVM. Instrução CVM n 358, de 3 de janeiro de 2002. Disponível em: $<$ http://www.cvm.gov.br>. Acesso em: 16 jun. 2013.

CORE, J. E.; HOLTHAUSEN, R. W.; LARCKER, D. F. Corporate governance, chief executive officer compensation and firm performance. Journal of financial economics, v. 51, n. 3, p. 371-406, 1999.

DAHER, W.; KARAM, F.; MIRMAN, L. J. Insider trading with different market structures. International Review of Economics e Finance, v. 24, p. 143-154, 2012. 
EBRAHIM, A. Board of Directors Monitoring of CEO Insider trading: Before and After the Sarbanes-Oxley Act. 2012.

MALKIEL, Burton G.; FAMA, Eugene F. Efficient capital markets: A review of theory and empirical work. The Journal of Finance, v. 25, n. 2, p. 383-417, 1970.

FIDRMUC, J. P.; GOERGEN, M.; RENNEBOOG, L. Insider trading, news releases, and ownership concentration. The Journal of Finance, v. 61, n. 6, p. 2931-2973, 2006.

FINNERTY, Joseph E. Insiders and market efficiency. The Journal of Finance, v. 31, n. 4, p. 1141-1148, 1976.

GALDI, F. C. Estratégias de investimento em ações baseadas na análise de demonstrações contábeis: é possível prever o sucesso? 2008. Tese (Doutorado) - Universidade de São Paulo (USP), Faculdade de Economia, Administração e Contabilidade (FEA), São Paulo, 2008.

GREENE, W. H. Econometric Analysis. 5. ed. New York: Prentice Hall, 2008.

GROSSMAN, S. J.; STIGLITZ, J.E. On the impossibility of informationally efficient markets. The American Economic Review, v.70, n.3, p.393-408, Jun. 1980.

GUJARATI, D. N. Econometria básica. 3. ed. São Paulo: Makron Books, 2000.

GUNNY, K.; KE, B; ZHANG, T. Aggressive informed trading by corporate executives and shareholder value. 2009.

HAQUE, M.; HASSAN, M.K.; VARELA, O. Stability, volatility, risk premiums and predictability in Latin American emerging stock markets. Quarterly Journal of Business and Economics 40, p.23-44, 2001.

HAIR JR, J. F.; BABIN, B.; MONEY, A. H.; SAMOUEL, P. Fundamentos de métodos de pesquisa em administração. Porto Alegre: Bookman, 2005.

HEALY, P.; PALEPU, K. Information Asymmetry, corportate disclosure, and the capital markets: A review of the empirical disclosure literature. Journal of Accounting and Economics, v. 31, n. 1, p. 405-440, 2001.

HENDRIKSEN, E. S.; BREDA, M. F. V. Teoria da contabilidade. 5. ed. São Paulo: Atlas, 1999.

IUDÍCIBUS, S. Teoria da contabilidade. 6. ed. São Paulo: Atlas, 2000.

JAFFE, J. F. Special information and insider trading. The Journal of Business, v. 47, n. 3, p. 410-428, 1974.

LORIE, James H.; NIEDERHOFFER, Victor. Predictive and statistical properties of insider trading. JL \& Econ., V. 11, p. $35,1968$.

MALHOTRA, N. K. Pesquisa de Marketing: uma orientação aplicada. Tradução de Laura Bocco. 4. ed. Porto Alegre: Bookman, 2006.

MARTINS, G. A.; THEÓPHILO, C. R. Metodologia da investigação científica para as ciências sociais aplicadas. São Paulo: Atlas, 2007.

MOURA, H. H. A. F; SÁ, P. F. de. Uma análise do disclosure e do insider trading no Brasil. $1979.180 \mathrm{f}$. Dissertação (Mestrado) - Pontifícia Universidade Católica do Rio de Janeiro, Departamento de Ciências Jurídicas, Rio de Janeiro, 1979.

MPF-PGR. Disponível em: <http://noticias.pgr.mpf.mp.br/noticias/noticias-do-site/copy_of criminal/1802-11-2013-ex-executivos-da-sadia-sao-os-primeiros-condenados-por-insider-trading-nobrasil/?searchterm=sadia $>$. Acesso em: 11 ago. 2013.

OLIVEIRA, S. L. Tratado de metodologia científica. São Paulo: Pioneira, 2001.

PALEPU, K.; HEALY, P.The fall of Enron. Journal of Economic Perspectives, v. 17, n. 2, 2003.

PARENTE, Norma. Aspectos Jurídicos do “insider trading”. CVM, 1978.

PEREZ, M. M.; FAMA, R. Ativos intangíveis e o desempenho empresarial. Revista Contabilidade e Finanças, v.17, n.40, p. 7-24, 2006

PIOTROSKI, J. D.; ROULSTONE, D. T. Do insider trades reflect both contrarian beliefs and superior knowledge about future cash flow realizations? Journal of Accounting and Economics, v. 39, n. 1, p. 55-81, 2005.

PROENÇA, J.M.M. Insider trading: Regime Jurídico do Uso de Informações Privilegiadas no Mercado de 
Capitais. São Paulo: Quartier Latin, 2005.

RATNER, M., LEAL, R. P. C., 1999. Tests of technical trading strategies in the emerging equity markets of Latin America and Asia. Journal of Banking \& Finance 23, 1887.1905.

ROCHMAN, R. R.; EID JR, W. Insiders conseguem retornos anormais? Estudos de eventos sobre as operações de insiders das empresas de governança corporativa diferenciada da Bovespa. In: ENCONTRO NACIONAL DE ECONOMIA [PROCEEDINGSOFTHE 34TH BRAZILIAN ECONOMICS MEETING], 34., 2006, Salvador. Anais... Salvador: ANPEC 2006.

ROGOFF, D. L. The Forecasting Properties of Insiders' transactions. The Journal of Finance, v. 19, n. 4, p. 697 698, 1964.

SOUSA, N. A.; PINHO, R. M. Uma Análise do Equity Value to Book com Performance de Carteiras. 2008.

TELDER, A. L. O Insider trading: O alcance da proibição do uso de informações privilegiadas no mercado de capitais e a responsabilidade do insider. 2011. Dissertação (Mestrado). Nova Lima, 2011.

WERNECK, M. A.; NOSSA, V.; LOPES, A. B.; TEIXEIRA, A. J. C. Estratégia de investimentos baseada em informações contábeis: modelo residual income valuation - Ohlson versus r-score - Piotroski. Advances in scientific and applied accounting, v. 3, n. 2, p. 141-164, 2013.

WESTON, J. F.; BRIGHAM, E. F. Fundamentos da Administração Financeira. 10. ed. São Paulo: Makron Books, 2000.

WOOLDRIDGE, J. M. Introdução à econometria: uma abordagem moderna. Pioneira Thomson Learning, 2006. 